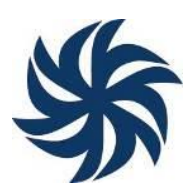

\title{
REPERTÓRIOS DE AÇÃO DOS PARLAMENTOS DIGITAIS BRASILEIROS DURANTE O ENFRENTAMENTO DA PANDEMIA
}

\author{
REPERTORIES OF ACTION OF BRAZILIAN DIGITAL PARLIAMENTS DURING \\ THE FACING OF THE PANDEMIC
}

\section{REPERTORIOS DE ACCIÓN DE LOS PARLAMENTOS DIGITALES BRASILEÑOS DURANTE EL ENFRENTAMIENTO DE LA PANDEMIA}

Sérgio Braga ${ }^{1}$

Fernando Wisse ${ }^{2}$

\begin{abstract}
Resumo: Este artigo busca mapear os repertórios de ação de enfretamento da Pandemia pelos parlamentos digitais brasileiros, com destaque para sua atuação nas mídias digitais, especialmente o Facebook. Para tanto, efetuamos uma análise de conteúdo dos portais parlamentares e das postagens do Facebook durante o período da Pandemia, do Senado Federal e da Câmara dos Deputados, de 27 Assembléias Legislativas e de 26 Câmaras Municipais das capitais brasileiras, buscando analisar os repertórios de ação disponíveis nesses parlamentos digitais para o enfrentamento da Pandemia. No tocante às postagens do Facebook, foram analisadas ao todo 15.996 postagens entre os meses de fevereiro a setembro de 2020. Os principais resultados apontam para uma intensa atuação dos parlamentos digitais efetuando ações durante a Pandemia, especialmente nas mídias digitais.
\end{abstract}

Palavra-chave: Covid-19; Parlamentos Digitais Brasileiros; Repertórios de ação de enfrentamento da Pandemia; Mídias digitais; Facebook.

\begin{abstract}
This article seeks to map the repertoires of action against Pandemic by Brazilian digital parliaments, with emphasis on their performance in digital media, especially Facebook. To this end, we conducted a content analysis of the parliamentary portals and Facebook posts during the period of Pandemic, the Federal Senate and the Chamber of Deputies, 27 Legislative Assemblies and 26 Municipal Councils in Brazilian capitals, seeking to analyze the available action repertoires in these digital parliaments to face the Pandemic. With regard to Facebook posts, a total of 15.996 posts were analyzed between February and September 2020. The main results point to an intense performance by digital parliaments during the Pandemic, carrying out several actions, especially in digital media.
\end{abstract}

Keywords: Covid-19; Brazilian Digital Parliaments; Repertoires of action to confront Pandemic; Digital media; Facebook.

Resumen: Este artículo busca mapear los repertorios de acción para combatir la pandemia de los parlamentos digitales brasileños, con énfasis en su desempeño en los medios digitales, especialmente Facebook. Para ello, realizamos un análisis de contenido de los portales parlamentarios y publicaciones de Facebook durante el período de Pandemia, el Senado Federal y la Cámara de Diputados, 27 Asambleas Legislativas y 26 Concejos Municipales en las capitales brasileñas, buscando analizar los repertorios de acción disponibles. en estos parlamentos digitales para hacer frente a la Pandemia. En cuanto a las publicaciones de Facebook, se analizaron 15.996 publicaciones entre febrero y septiembre de 2020. Los principales resultados apuntan a un intenso desempeño de los parlamentos digitales que llevan a cabo acciones durante la Pandemia, especialmente en los medios digitales.

\footnotetext{
${ }^{1}$ Sérgio Braga é Doutor em Desenvolvimento Econômico pelo IE Unicamp, Professor de Ciência Política do Programa de Pós-Graduação em Ciência Política (PPGCP) da UFPR, e bolsista produtividade nível 2 do CNPq. Email: sssbraga@gmail.com.

${ }^{2}$ Fernando Wisse é doutorando em Ciência Política pelo PPGCP-UFRP. E-mail: fernandowisse@gmail.com.
} 
Palabra clave: Covid-19; Parlamentos digitales brasileños; Repertorios de acción para enfrentar la pandemia; Medios digitales; Facebook.

\section{Introdução: os parlamentos digitais no contexto de enfretamento da Pandemia ${ }^{3}$.}

A conjuntura de enfrentamento ao Coronavírus tem sido objeto de uma série de estudos abordando os mais diferentes aspectos da questão. Entretanto, apesar da grande quantidade de trabalhos sobre o assunto e seus impactos na administração pública, ainda são poucas as pesquisas abordando especificamente a questão de como os parlamentos estão lidando com o tema, especialmente os parlamentos digitais ${ }^{4}$. Esse problema é especialmente importante num contexto onde o parlamento tem servido como anteparo para medidas de enfrentamento e gerenciamento da crise por lideranças políticas e chefes de governo que, de uma perspectiva negacionista, muitas vezes adotam modalidades populistas no enfrentamento da pandemia, buscando utiliza-la como uma janela de oportunidade para o acúmulo de capital político, visando a disputas políticas e eleitorais futuras ${ }^{5}$ Como observado por esses estudos recentes, a pandemia afetou múltiplos aspectos da vida social, colocando a digitalização das atividades humanas em geral, e da administração pública em particular, em novos patamares (MEDEIROS et al., 2020; PEREIRA, et al., 2020). No caso dos parlamentos digitais, isso não é diferente. Consolidando tendências anteriores de digitalização das atividades parlamentares (BRAGA, MITOZO; TADRA, 2016), os parlamentos brasileiros rapidamente se adaptaram ao novo contexto, tendo sido os primeiros parlamentos do mundo a realizar sessões remotas para organizar suas atividades (PEIXOTO, 2020). Esse comportamento ágil também foi adotado nas esferas subnacionais de governo e de representação política, com diversas Assembleias Legislativas em escala subnacional realizando sessões remotas, dentre outras atividades de enfrentamento da Pandemia (MITOZO, 2020). Como também constatam esses estudos, os

\footnotetext{
${ }^{3}$ Este artigo foi elaborado no âmbito do projeto de pesquisa "Profissionalização política, tecnologias digitais e as funções desempenhadas pelos e-parlamentos: um estudo comparado das Assembléias e Câmaras Legislativas brasileiras (2019-2023)", financiado pelo CNPq (Chamada CNPq 06/2019 - Bolsas de Produtividade em Pesquisa, processo 311675/2019-0). Agradecemos aos bolsistas Rafael Linhares (PIBIT- UFPR), Maria Cristina Gomes Cassaro (PIBIC-UFPR), Hanna Marcon (PIBIT-UFPR), João Felipe Kahali (Fundação Araucária-UFPR) e Mayara Gomes (pesquisadora voluntária-UFPR) que auxiliaram no processo de coleta de dados para elaboração deste artigo no período de junho a setembro de 2020. Gostaríamos, por fim, de agradecer às meticulosas observações ao texto feita pelos pareceristas anônimos da revista E-legis.

${ }^{4}$ Cf. o número especial organizado pela Revista de Administração Pública da FGV contendo diversos estudos sobre as estratégias de enfretamento e gerenciamento da Covid-19 por vários órgãos da Opinião Pública: http://bibliotecadigital.fgv.br/ojs/index.php/rap/issue/view/4511 (acesso em: setembro de 2020). O site da ABCP/Associação Brasileira de Ciência Política, publicou uma importante sequência de estudos sobre as medidas para o enfretamento da Covid-19 tomadas pelos governos estaduais brasileiros; entretanto, salvo engano, não abordou a questão dos parlamentos estaduais: https://cienciapolitica.org.br/noticias/2020/06/especial-abcp-governosestaduais-e-acoes-enfrentamento (acesso em: setembro de 2020). Sobre as medidas tomadas pelo parlamento, com foco no problema das sessões remotas, conferir os trabalhos de Mitozo (2020), Peixoto (2020) e Santos (2020)

${ }^{5}$ Para uma análise das modalidades de enfrentamento da Pandemia por líderes políticos populistas, de esquerda e de direita, conferir o trabalho de Brett Meyer (MEYER, 2020) Para um estudo sobre a possibilidade dos parlamentos digitais de "achatarem" a "curva autoritária" de líderes plebiscitários, cf. o instigante texto de Tiago Peixoto, em quem nos inspiramos grandemente para a feitura desta pesquisa.
} 
parlamentos digitais foram importantes para a busca de soluções negociadas e consensuais para o enfretamento da Pandemia, muitas vezes retificando ou alterando medidas tomadas pelos órgãos governamentais, que tiveram elevado impacto social. O caso mais notório é o da aprovação, pelo Congresso Nacional, do auxílio de $\mathrm{R} \$ 600,00$ aos atingidos pela pandemia, em contraposição à medida mais restritiva inicialmente projetada pelo Governo Federal de conceder apenas R \$200,00 de auxílio, onde as sessões remotas organizadas pelo Congresso Nacional desempenharam papel fundamental, ao lado de outros fatores (BRASIL, 2020).

Nesse contexto de elevação da digitalização das atividades parlamentares para novos patamares, cujo aspecto mais visível é a realização de sessões deliberativas remotas, o objetivo deste artigo é aprofundar a abordagem desse tema, com foco em dois aspectos específicos: a) Como os parlamentos digitais utilizaram suas plataformas (portais e mídias digitais) para divulgar ações contra a Pandemia; b) Como os parlamentos digitais usaram uma mídia digital específica (no caso, o Facebook), para divulgar ações de enfrentamento e quais dessas ações reverberaram nas redes. Procuramos analisar os portais dos órgãos parlamentares e as redes digitais conjuntamente, porque nossa intenção neste artigo não é apenas fazer uma prospecção descritiva do conjunto de iniciativas efetuadas nos portais dos órgãos parlamentares, mas, principalmente, a de mapear as ações mais importantes que reverberaram na esfera pública digital e avaliar seu impacto, tal como mensurado pelo engajamento gerado nas postagens do Facebook.

Para concretizar esses objetivos, efetuamos uma análise de conteúdo dos websites de 2 parlamentos federais (Câmara dos Deputados e Senado Federal), 27 assembléias legislativas, e 26 câmaras municipais das capitais dos estados. Além disso, analisamos 15.988 postagens no Facebook desses órgãos entre o dia 26 de fevereiro (data da primeira confirmação de que a doença havia chegado ao país) e $1^{\circ}$ de setembro de 2020 , respectivamente data de início das medidas tomadas pelos órgãos parlamentares para enfrentar a pandemia e data do encerramento da coleta de dados para nossa pesquisa. Analisaremos as plataformas digitais dos órgãos nacionais e subnacionais conjuntamente porque um dos objetivos centrais deste texto é o de verificar se as iniciativas empreendidas em escala nacional pelo Senado Federal e pela Câmara dos Deputados, que possuem maior impacto e repercussão junto à opinião pública, também reverberaram ou foram reproduzidas em nível dos estados e municípios. Por este motivo, analisamos os parlamentos nacionais em conjunto com os estaduais e das capitais dos estados.

Nas páginas seguintes, após uma breve discussão teórico-metodológica, apresentamos as evidências coletadas sobre o tema. 


\section{E-parlamentos e governança digital.}

Desde, pelo menos, os anos 1990, uma crescente literatura tem analisado os parlamentos online, abordando o problema em múltiplas dimensões. Apesar das percepções vigentes no senso comum e da ampla literatura científica surgida recentemente sobre o "desengajamento cívico em relação aos partidos e à política" (DANTON; WATTENBERG, 2000) sobre a "crise de representação" (CASTELLS, 2018) e, em sua versão mais recente e pessimista, sobre a “morte das democracias" (PERSILY, 2017; LEVITSKY; ZIBLATT, 2018), o fato observável é que, pelo menos até o momento da redação deste texto, os parlamentos têm funcionado de maneira regular nos sistemas políticos do mundo (inclusive em países que não podem ser considerados plenamente democráticos). $\mathrm{E}$ as plataformas digitais dos órgãos parlamentares têm se tornado, inclusive, pelo menos até aqui, universalmente difundidas, contribuindo para o aumento da visibilidade e da importância destas instituições nos sistemas políticos contemporâneos (ALCÁNTARA SAEZ; GARCÍA MONTERO, 2013; COLEMAN, 2017).

Neste novo contexto de instabilidade das instituições democráticas tradicionais, mais do que uma "crise" final das democracias representativas, onde as instituições representativas tradicionais são substituídas por instituições inteiramente novas ou mesmo por regimes autoritários e iliberais, o que observamos é uma nova metamorfose da democracia representativa, para usar a terminologia de Bernard Manin, onde a "democracia de público" tradicional dá lugar a novas modalidades de instituições representativas, caracterizadas por alguns autores como "democracia monitorada", ou "democracia híbrida" (KEANE, 2013; CHADWICK, 2017), com uma crescente plataformização dos atores e instituições políticos, que torna possível e necessário o surgimento de novos repertórios de ação política e coletiva por parte não apenas dos atores sociais, mas também de instituições representativas como partidos políticos e órgãos legislativos (GERBAUDO, 2018; MENDONÇA; FREITAS, 2019).

Nesse contexto, as experiências de gerenciamento da atividade parlamentar e o processo de digitalização e "plataformização" crescentes das instituições representativas colocam aos pesquisadores envolvidos nesse campo múltiplos desafios, apontando para uma ampla agenda de reflexão e de pesquisa, abrangendo estudos de caso e comparados, tanto qualitativos como quantitativos. Esses desafios se tornam ainda mais prementes de serem enfrentados no recente contexto de crise sanitária global do Coronavírus, quando parlamentos do Brasil e de vários países do mundo usaram intensivamente as tecnologias digitais para implementarem um amplo repertório de ações que contribuíram decisivamente para o enfrentamento da pandemia (PEIXOTO, 2020; WILLIAMSON, 2020). Desse modo, favoreceram um contexto de afirmação das instituições democráticas, contribuindo para a visibilidade das instituições parlamentares, assim como para sua integração com outros órgãos da administração pública. Podemos mesmo afirmar que os parlamentos digitais estão entre os atores mais importantes para o enfretamento 
da Pandemia, tomando várias medidas de elevado impacto social para o enfretamento da Covid19, ao lado de outros atores das esferas política e civil (WILLIAMSON, 2020).

Nesse contexto, hospedar um parlamento remoto é um desafio. Não existem soluções digitais instantâneas que façam um parlamento funcionar virtualmente. Os parlamentos são, historicamente, lugares onde os representantes debatem e aprovam leis de forma presencial, onde a deliberação e os encontros face-a-face têm importante papel para o desempenho de suas funções parlamentares (NORTON, 1990; LESTON-BANDEIRA, 2007). Mesmo assim, a utilização de plataformas digitais mostrou-se fundamental para a continuidade do trabalho parlamentar em tempos de pandemia, tendo sido amplamente utilizadas pela maior parte dos parlamentos do mundo para a implementação de várias decisões e estratégias de comunicação pelos órgãos legislativos. Essas estratégias têm se concentrado no compartilhamento de informações vitais sobre saúde, inclusive por meio do uso de media digitais para ajudar a publicitar as decisões do parlamento, como veremos neste artigo. Como as tecnologias digitais, incluindo ferramentas eletrônicas, sistemas, dispositivos e recursos que geram, armazenam ou processam dados, têm o potencial de transcender as barreiras físicas e, até certo ponto, financeiras, ao fornecer informações em tempo real, elas foram adotadas em vários setores, inclusive na comunicação institucional via redes sociais digitais, como Facebook, Twitter e YouTube e, mais recentemente, Instagram e WhatsApp.

Nesse sentido, foram realizadas uma série de ações para o enfretamento da Covid-19 em diversas unidades de governo. A mais visível delas são as sessões remotas utilizando plataformas de transmissão digital, que já foram objeto de estudos por outros pesquisadores (MITOZO, 2020; PEIXOTO, 2020; SANTOS, 2020). Entretanto, esses trabalhos se concentram em órgãos de maior visibilidade, tais como a Câmara dos Deputados e algumas assembleias legislativas (tais como as Assembleia Legislativa do Paraná), onde os parlamentos já atingiram há tempos critérios de excelência no processo de digitalização de suas atividades ${ }^{6}$. As questões que colocamos aqui são de natureza um pouco diferente e, de certo modo, complementares às colocadas por esses pesquisadores. Perguntamos: esses processos de digitalização das atividades para o enfretamento da Pandemia estão se difundindo para outros legislativos subnacionais, inclusive as câmaras municipais? Esses parlamentos estão usando as mídias digitais para engajar o cidadão em medidas de combate à Covid-19 e informá-los das ações e iniciativas efetuadas para o enfrentamento da Pandemia?

Para abordar essas questões mais gerais, este artigo busca mapear os repertórios de ação de enfretamento da Pandemia pelos parlamentos digitais brasileiros, com destaque para sua atuação nas mídias digitais, especialmente o Facebook. Para tanto, efetuamos uma análise de

\footnotetext{
${ }^{6}$ Para um estudo estabelecendo um ranqueamento das diferentes funções desempenhadas pelos parlamentos digitais brasileiros nas esferas estaduais e municipais cf. os trabalhos de Braga, Mitozo e Tadra (2016) e Mitozo, Braga \&
} 
conteúdo dos portais e das postagens do Facebook durante o período da Pandemia, do Senado Federal e da Câmara dos Deputados, de 27 Assembleias Legislativas e de 26 Câmaras Municipais das capitais brasileiras, buscando analisar os repertórios de ação disponíveis nesses parlamentos digitais para o enfrentamento da Pandemia ${ }^{7}$. No tocante às postagens do Facebook, foram analisadas ao todo 15.996 postagens entre os meses de fevereiro a setembro de 2020 . No item seguinte, procuraremos apresentar alguns dos principais resultados da pesquisa efetuada

Sendo assim, o presente artigo possui as seguintes questões de pesquisa:

Q01: Como os portais parlamentares em escala nacional e subnacional usaram suas plataformas digitais para divulgar diferentes ações e iniciativas para o enfretamento da covid$19 ?$

Q02: Os parlamentos subnacionais (Assembleias e Câmaras Legislativas) replicaram e reproduziram as ações dos parlamentos nacionais (Senado Federal e Câmara dos Deputados)?

Para respondermos a essas questões, desenvolvemos a seguinte metodologia: a) inicialmente, efetuamos uma análise de conteúdo dos portais dos parlamentos mencionados, procurando verificar quais ações de enfrentamento da Pandemia foram divulgadas em tais plataformas, durante os meses de junho a setembro de 2020; b) em seguida, efetuamos uma análise de uma das mídias digitais mais utilizadas pelos parlamentos e pelos cidadãos (no caso, o Facebook), para verificar se esses repertórios reverberaram além dos portais parlamentares e com qual intensidade.

Como o objetivo central deste texto não é realizar uma prospecção que mapeie todas as ações desenvolvidas pelos parlamentos digitais, escolhemos inicialmente um total de 10 variáveis para analisar o conteúdo dos portais parlamentares. Os critérios de seleção das variáveis foram algumas ações mais relevantes mencionadas em matérias da mídia e nos portais das duas casas legislativas brasileiras mais importantes (Senado Federal e Câmara dos Deputados). Essa análise de conteúdo foi efetuada pela equipe de pesquisadores citada no início deste artigo e submetida a uma checagem pelos autores do artigo. Em seguida, coletamos todas as postagens efetuadas nos Facebooks das casas legislativas examinadas e efetuamos uma busca por termos-chave para verificar a menção a termos associados à Pandemia. Cabe esclarecer que, dado o caráter exploratório deste estudo, destinado a mapear repertórios de ação e iniciativas

\footnotetext{
Tadra (2016a).

${ }^{7}$ Definimos "Parlamento Digital" como o uso das plataformas digitais pelos órgãos parlamentares para gerenciar múltiplos aspectos de suas atividades e de sua governança, tanto "internos" e não visíveis ao público, como abertos e transparentes a ele. $\mathrm{O}$ aspecto mais visível dos parlamentos digitais são os portais parlamentares, que usamos como unidade de análise básica deste artigo. Estes portais parlamentares, por sua vez, tornam possíveis vários repertórios de ação, conceito inicialmente elaborado por Charles Tilly para a análise do ativismo social, mas que tem sido empregado recentemente por diversos autores para analisar as iniciativas e atividades dos atores políticos num contexto de democracia digital e de plataformização da ação coletiva (MENDONÇA; FREITAS, 2019).
} 
implementadas pelos legislativos, não procuramos testar hipóteses sobre os possíveis fatores determinantes da frequência e da intensidade de tais iniciativas, ou mesmo sobre os impactos ou efeitos de cada uma delas. Dados os limites de espaço e o escopo do presente artigo, acreditamos que as respostas a essas indagações seriam motivo para outros estudos mais aprofundados a serem ulteriormente empreendidos no âmbito da presente investigação.

Feitos esses esclarecimentos sobre o desenho de nossa pesquisa, podemos passar à exposição de alguns de seus resultados.

\section{Análise dos Resultados}

Neste item, procuraremos apresentar algumas evidências que nos permitam responder às seguintes indagações: a) quais as principais ações divulgadas pelos parlamentos através de suas páginas e com qual frequência e intensidade?; b) qual a relação entre números de postagens no Facebook durante o período da Pandemia e o engajamento obtido por tais plataformas, entendido como o número de reações provocadas por cada postagem durante o período examinado; c) do conjunto de postagens efetuadas pelas casas legislativas durante a pandemia, quais delas tratam da Covid-19?; d) Quais os principais temas tratados e iniciativas tomadas nas redes digitais pelos parlamentos durante a Pandemia e quais provocaram maior engajamento e impacto nas redes sociais?

Em relação ao primeiro ponto, fizemos uma análise de conteúdo dos portais de 55 parlamentos digitais durante a Pandemia com o objetivo de mapear o repertório de ações divulgados pelos mesmos para o enfrentamento do Covid-19, chegando aos seguintes resultados: 
Tabela 1 - Principais ações divulgadas nos e-parlamentos durante a pandemia

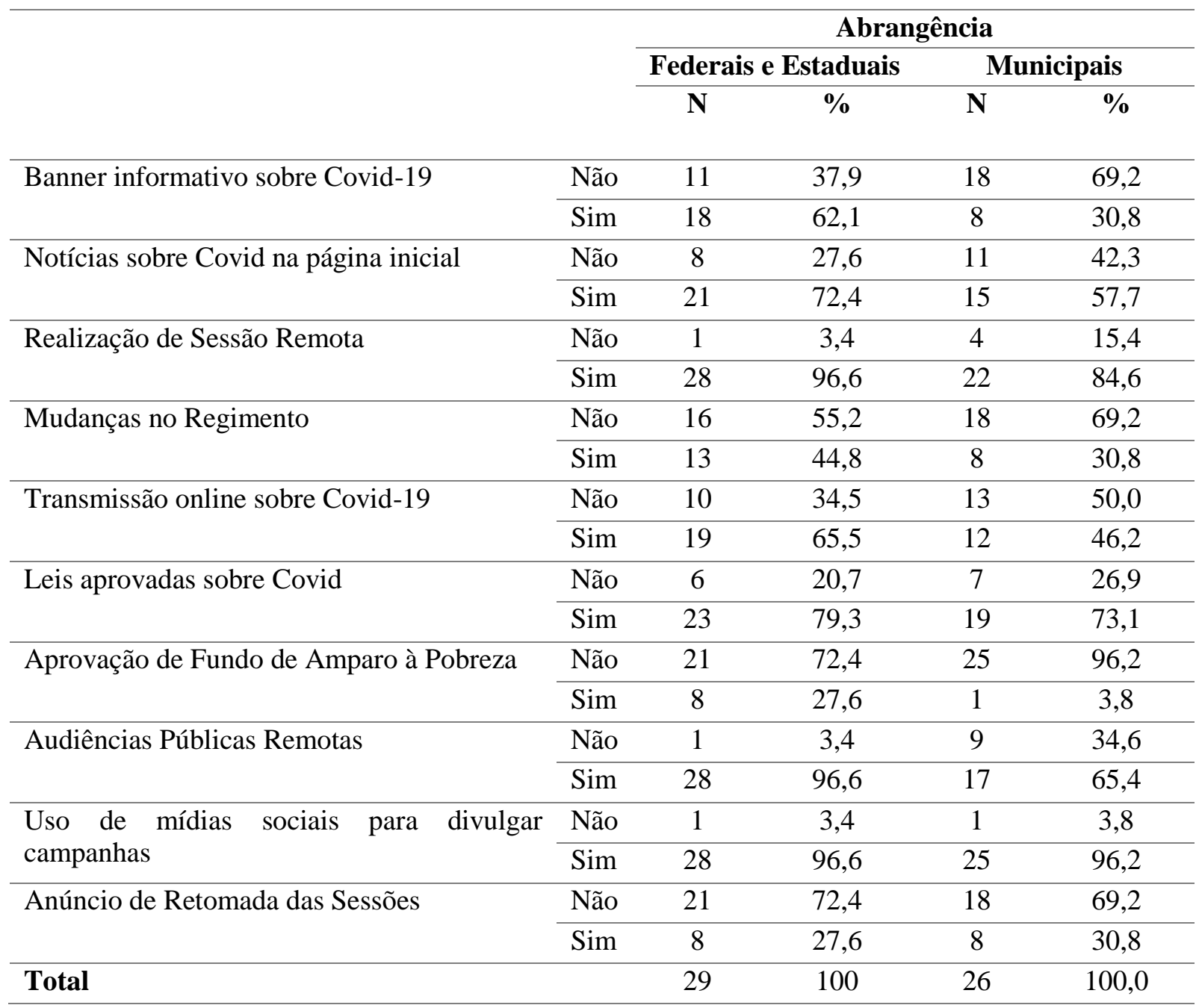

Fonte: Base de Dados do Grupo de Pesquisa.

A tabela acima nos informa a frequência de algumas das principais iniciativas veiculadas nos portais parlamentares para o enfretamento da Pandemia durante o período pesquisado. Deve-se observar que muitas das assembleias empreenderam tais ações, entretanto estas não foram divulgadas em seus portais. Em nosso trabalho, mapeamos apenas aquelas que foram objeto de divulgação em suas plataformas digitais. As casas legislativas de abrangência federal e estadual, de maneira geral, apresentaram mais informações sobre as ações parlamentares para combater à pandemia. Uma iniciativa importante foi o uso de banners pelas Assembleias para divulgar as ações de enfretamento da Covid como, por exemplo, esta figura divulgada no site da Assembleia Legislativa do Paraná durante praticamente todo o período da Pandemia resumindo as principais iniciativas implementadas pelo órgão no período da Covid$19^{8}$.

\footnotetext{
${ }^{8}$ Banners digitais são ferramentas de divulgação de iniciativas e ações que podem ser criadas para publicação em sites e portais na internet. Especialistas afirmam que, no contexto do banner digital, os banners na internet podem ser
} 
Figura 1 - "Banner" da ALEP divulgando ações sobre pandemia em sua página inicial.

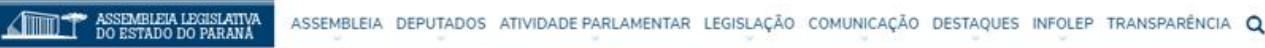

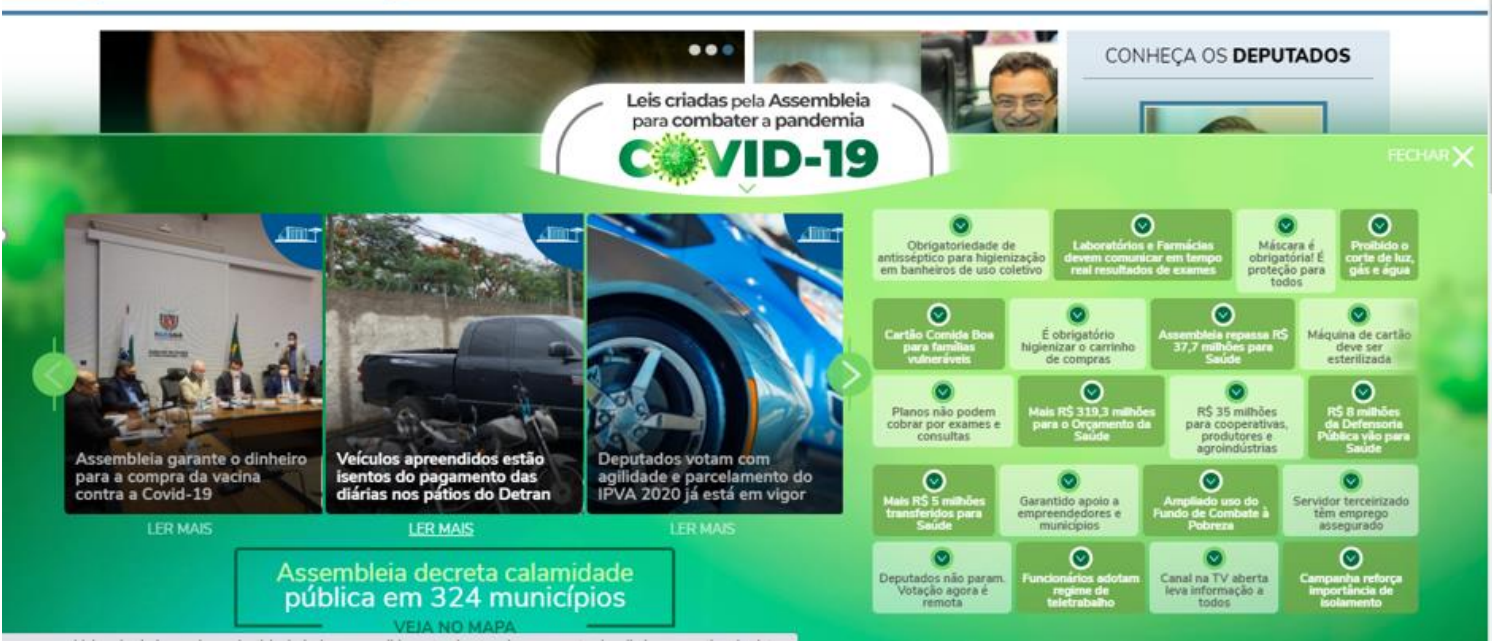

Fonte: Portal da ALEP.

Com efeito, nesse banner estão enumeradas diversas iniciativas tomadas pela Assembleia Legislativa do Paraná para o enfretamento da Pandemia, muito além da realização das mais visíveis "sessões remotas", tais como: a) aprovação de diversas leis e medidas para o enfrentamento do Coronavirus; b) decretação de estado de calamidade pública em municípios; c) adoção da votação nominal remota; d) ampliação do Fundo de Combate à Pobreza; e) isenção de taxas para exames e consultas, dentre outras medidas de apoio ao usuário e cidadão comum que vão muito além de meras ações de gerenciamento da atividade parlamentar quotidiana por meio de plataformas digitais. Essas atividades, ao lado de outras, tiveram amplo impacto social no estado, contribuindo para o aumento visibilidade do órgão parlamentar, e muitas vezes questionando e "problematizando" medidas tomadas pelo governo, afetando a vida de milhares de pessoas muito além da esfera digital.

Outro exemplo de "boa prática" do uso de banners para divulgação de iniciativas relacionadas ao enfrentamento da Pandemia, que também serviu de base para definirmos nossas variáveis de análise, foi o do programa "Plantão permanente contra o coronavírus", implementado pela Assembleia Legislativa da Bahia, que serviu de ferramenta para a veiculação de diversas ações de controle do Coronavírus, conforme ilustrado pela figura abaixo.

estáticos, animados, interativos ou seguir o padrão de Pop-Up (não propriamente um banner, mas ainda assim uma peça eletrônica). Dentre estes, os banners animados e/ou interativos são os que chamam mais a atenção e consequentemente trazem mais resultados (cf. o site: https://conceitoideal.com.br/. Acesso em outubro de 2020). 
Figura 2 - Banner do "Plantão permanente contra o Coronavírus", divulgado pela ALEBA

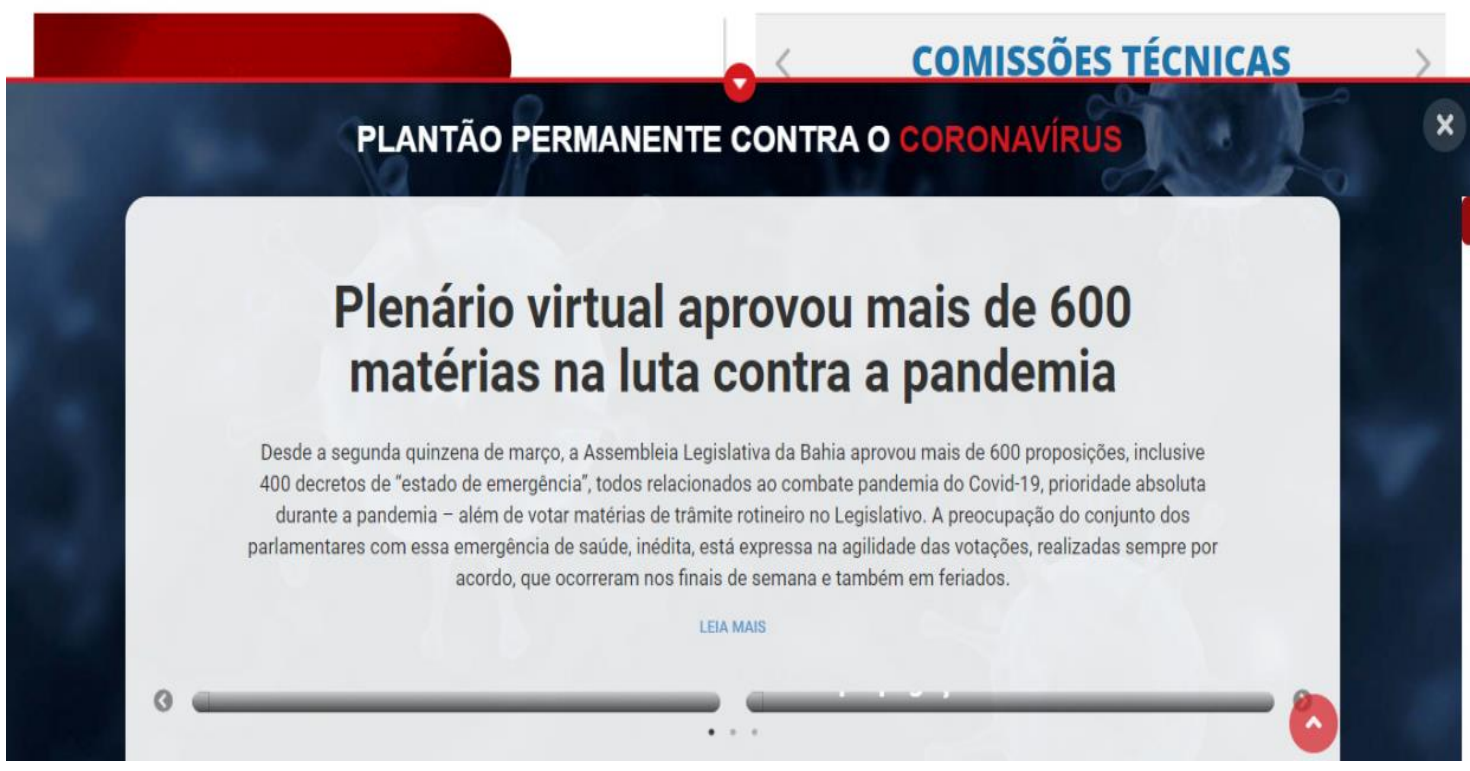

Fonte: Portal da ALEBA.

Como pode ser visto na tabela 1 acima, uma atividade de destaque empreendida pelos parlamentos foi o uso das mídias digitais para a promoção de campanhas de engajamento do público em ações de combate à Covid-19. Com efeito, a literatura sobre parlamentos digitais tem observado o crescente uso das mídias digitais para estimular o engajamento dos cidadãos nas atividades do parlamento, ao lado do amplo uso das redes digitais pelos próprios parlamentares (LESTON-BANDEIRA, 2013; 2018). Nesse sentido, Facebook, Twitter, Instagram e Canais do Youtube foram intensamente utilizados por diferentes parlamentos, com graus diferentes de intensidade, para engajar o público em ações de combate ao Covid-19. Para este texto, nos concentramos nas postagens do Facebook, na medida em que praticamente todos os órgãos legislativos examinados possuem presença nessa mídia digital.

Como pode ser verificado no anexo 01 a este artigo, apenas a Câmara Municipal de Rio Branco não teve Facebook ativo durante o período de nossa pesquisa. Como mostra a tabela a seguir, o Facebook foi a segunda mídia digital mais utilizada no mesmo período, em seguida ao Youtube, que teve grande número de visualizações no período, especialmente os canais dos parlamentos nacionais. 
Tabela 2 - Uso das principais mídias digitais pelos legislativos brasileiros durante a pandemia (média e desvio padrão de usuários).

\begin{tabular}{clcccc}
\hline \multicolumn{2}{c}{ Abrangência } & $\begin{array}{c}\text { Seguidores } \\
\text { no Facebook }\end{array}$ & $\begin{array}{c}\text { Seguidores } \\
\text { no Twitter }\end{array}$ & $\begin{array}{c}\text { Visualizações } \\
\text { no Youtube }\end{array}$ & $\begin{array}{c}\text { Seguidores } \\
\text { no } \\
\text { Instagram }\end{array}$ \\
\hline \multirow{3}{*}{ Federal } & Média & 3.729 .155 & 978.272 & 76.435 .814 & 847.863 \\
& N & 2 & 2 & 2 & 2 \\
& Desvio Padrão & 4.037 .740 & 34.032 & 35.624 .646 & 1.063 .683 \\
& Média & 57.097 & 13.990 & 2.416 .024 & 15.917 \\
Estadual & N & 27 & 26 & 25 & 26 \\
& Desvio Padrão & 60.899 & 24.380 & 4.101 .966 & 12.573 \\
& Média & 38.400 & 6.043 & 448.559 & 6.318 \\
& N & 26 & 20 & 25 & 21 \\
& Desvio Padrão & 101.843 & 6.933 & 1.134 .874 & 11.088 \\
& Média & 181.788 & 50.857 & 4.317 .042 & 45.760 \\
& N & 55 & 48 & 52 & 49 \\
& Desvio Padrão & 890.080 & 196.384 & 15.699 .733 & 227.321 \\
\hline
\end{tabular}

Fonte: Base de Dados do Grupo de Pesquisa

Um primeiro dado relevante sobre a atuação dos parlamentos no Facebook pode ser dado pelo diagrama abaixo, ilustrando a relação entre as postagens no Facebook e o engajamento obtido no período, tal como mensurado pelo número de seguidores e "curtidas" nas páginas do Facebook das casas legislativas que estiveram ativas no período (RECUERO, 2010). É importante esclarecer que ao longo deste texto utilizaremos a quantidade de postagens e reações nos Facebooks dos parlamentos como proxy da intensidade do comprometimento das assembleias no desencadeamento de ações sobre a Pandemia. 
Figura 3 - Relação entre postagens e presença no Facebook.

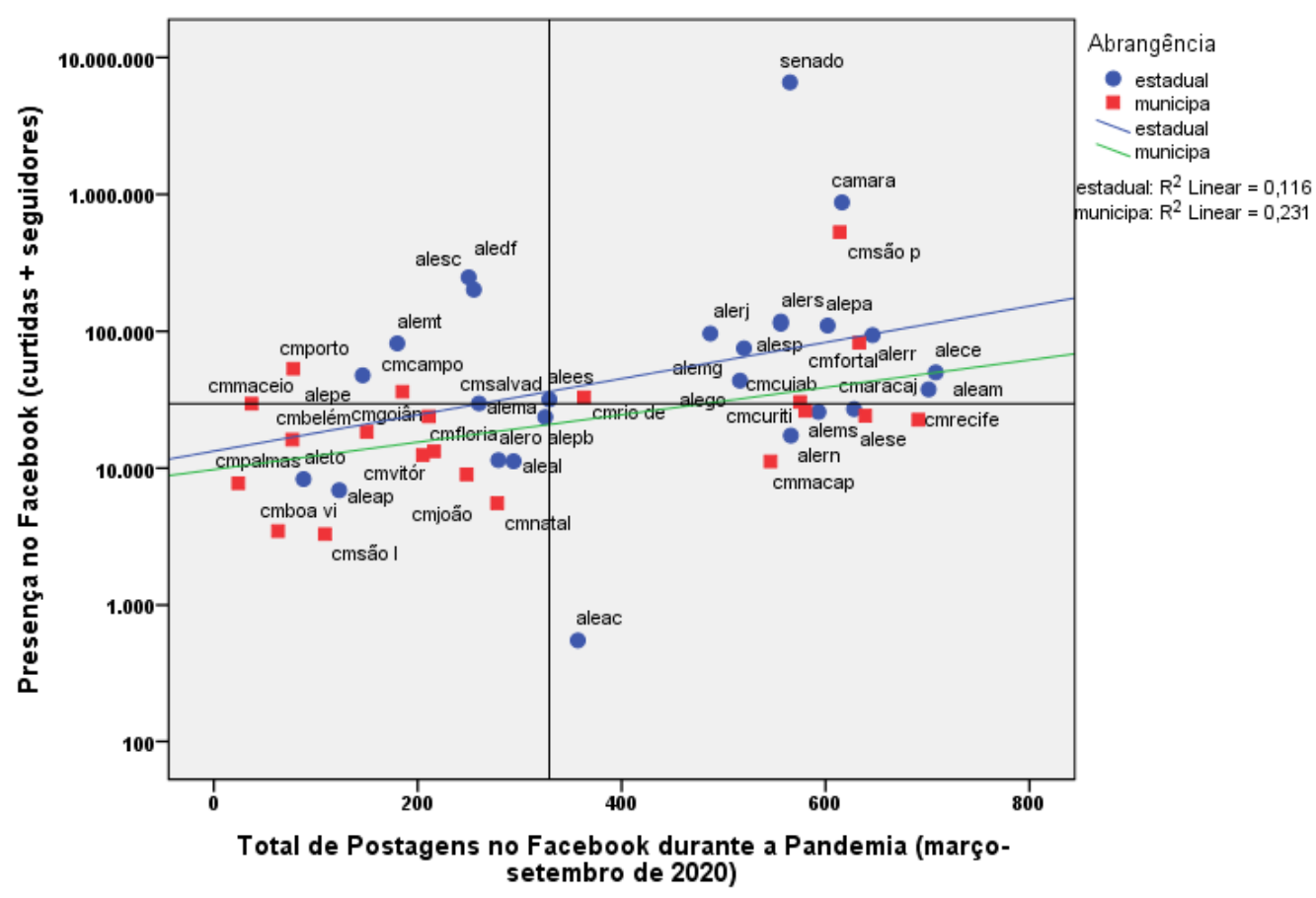

Fonte: Base de Dados do Grupo de Pesquisa.

No tocante a esse ponto, podemos detectar quatro subgrupos de parlamento, localizados em cada lado do quadrante: a) aqueles que postaram muito no período e conseguiram elevado índice de engajamento, localizados no primeiro quadrante, destacando-se o Senado Federal, a Câmara dos Deputados, a Câmara Municipal de São Paulo e outros órgãos; b) aqueles parlamentos que postaram acima da média, mas tiveram fraco engajamento no período em tela; c) os órgãos legislativos que postaram pouco e tiveram pouco engajamento, no terceiro quadrante; d) e, por fim, aqueles que postaram abaixo da média, mas obtiveram elevado índice de engajamento das postagens, tais como a ALESC e a ALEDF.

Outra questão relevante é a de se temas relacionados à Covid-19 foram abordados nas postagens efetuadas pelos Facebooks das Assembleias durante o período pesquisado (final de fevereiro de 2020 à primeira semana de setembro). Para verificar essa questão, realizamos uma busca com os temos "Covid-19", "coronavírus", "pandemia", "vírus" e outros termos associados, nas postagens realizadas nos Facebooks das diferentes Assembleias. Os resultados estão apresentados na figura abaixo: 
Figura 4- Postagens sobre a Covid do total de postagens

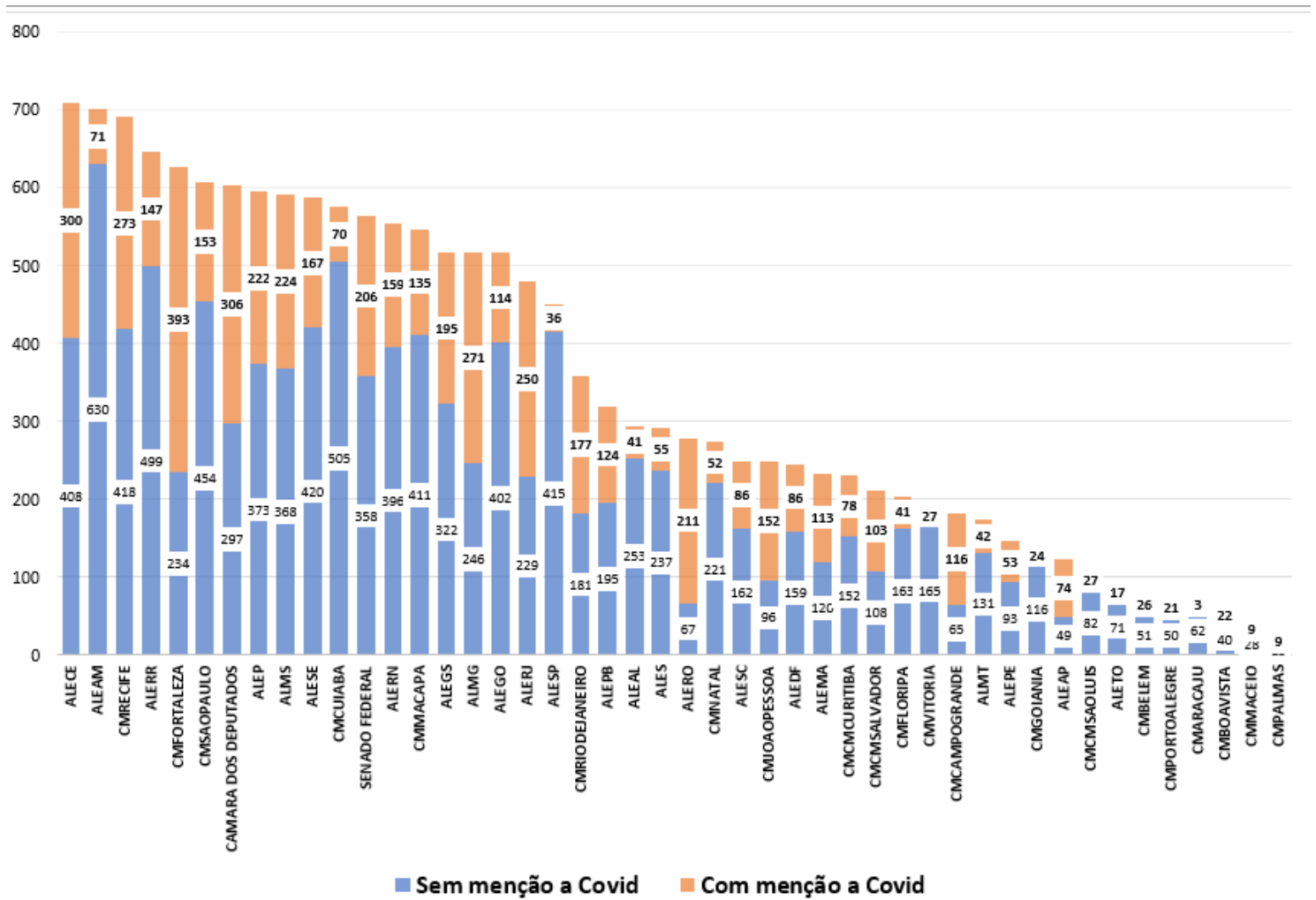

Fonte: Elaboração própria.

Observamos que, do total de 15.996 postagens realizadas pelos diversos parlamentos no período (Senado Federal e Câmara dos Deputados, Assembleias e Câmaras Municipais das capitais), cerca de 5.484 delas referiam-se à Pandemia, o que pode ser considerado um percentual relevante, dado que indica a intensa presença de postagens sobre o tema na timeline dos parlamentos durante o período de isolamento social. Do ponto de vista absoluto, os parlamentos que mais postagens fizeram sobre medidas de enfrentamento a Covid-19sobre a pandemia foram, respectivamente, Câmara Municipal de Fortaleza (393), a Câmara dos Deputados (306), Assembleia Legislativa do Ceará (300) e Câmara Municipal de Recife (273), não por acaso parlamentos situados em regiões fortemente afetadas pelo Coronavirus ou então órgãos nacionais com maior visibilidade nacional que divulgaram intensamente medidas de combate à Pandemia. No espaço do presente texto, cabe observar estas diferentes, ficando para estudos posteriores uma análise mais aprofundada sobre as possíveis causas destes padrões diferenciados.

Do ponto de vista relativo, ou seja, em temos de percentual de postagens elas estão informadas na tabela abaixo, com padrões um pouco diferentes do anteriores, pois em termos relativos a Assembléias Legislativas do Amapá e de Roraima, e as Câmaras Municipais de Campo Grande, de São Luís e João Pessoa, foram as que mais postaram. Entretanto, no âmbito do presente artigo, cabe apenas detectar estes diferentes padrões, ficando para estudos 
posteriores uma reflexão de suas eventuais causas. Entretanto, optamos por manter estes dados, pois eles ilustram uma das proposições centrais do artigo de que diferentes órgãos parlamentares repercutiram de forma diversa as medidas de enfrentamento sobre a Pandemia adotadas em nível nacional.

Figura 5- Postagens sobre a Covid do total de postagens (\%).

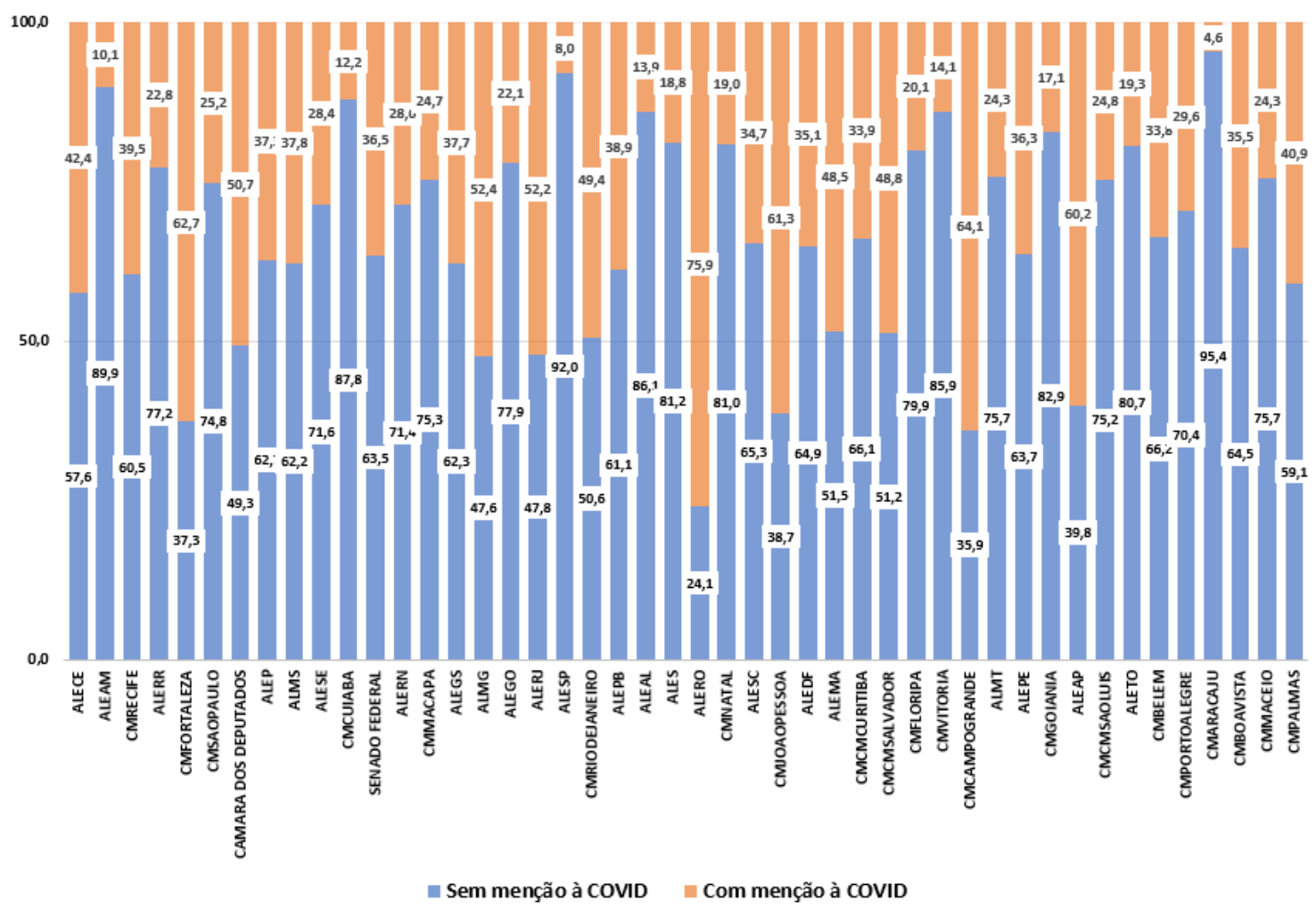

Fonte: Base de Dados do Grupo de Pesquisa (GAP).

Por fim, podemos fazer uma análise de cunho qualitativo dos principais temas abordados nas postagens durante o período da Pandemia, a partir da nuvem de palavras formada a partir dos temas mais relevantes tratados nas postagens sobre o Covid-19 no período analisado. 
Figura 6-Temas tratados no Facebook (nuvem de palavras).

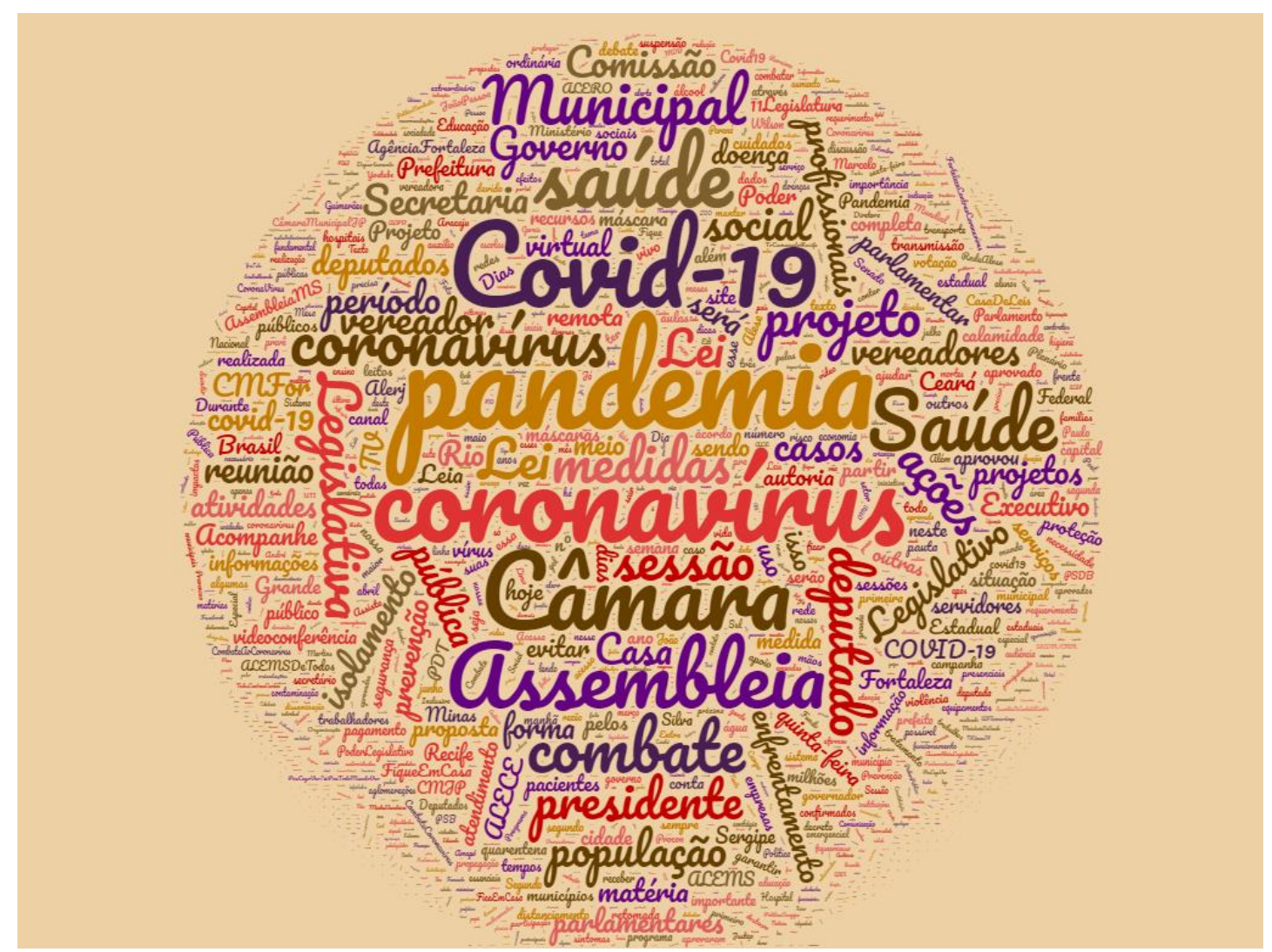

Fonte: Elaboração própria.

A partir da nuvem de palavras das postagens sobre o Covid-19 no Facebook dos parlamentos examinados, podemos mapear algumas das ações desencadeadas e de maior impacto sobre os cidadãos nas redes sociais. Podemos observar os termos "sessão", "remota", "medidas", "lei" associados de maneira mais forte às expressões relacionadas ao Covid-19. Além do perfil informativo sobre o vírus e a doença, o foco das postagens estava na atividade legislativa empreendida nas reuniões parlamentares modificadas, principalmente em categorias como: (1) a aprovação de medidas fiscais regulares e (2) a aprovação de alterações legislativas emergenciais relacionadas ao COVID. As medidas fiscais incluíram orçamentos e atualizações fiscais, aprovação de estimativas e a autorização de iniciativas fiscais. A legislação de emergência relacionada ao COVID-19 incluiu mudanças na legislação trabalhista e legislação de medidas de emergência em resposta aos impactos da pandemia. As postagens de maior impacto durante o período da Pandemia foram postagens do Senado e da Câmara dos Deputados informando o resultado de sessões deliberativas virtuais. Destaca-se como postagem de maior impacto o post: “Acompanhe ao vivo a sessão do \#PlenárioVirtual da Câmara dos Deputados. $\mathrm{Na}$ pauta, projetos de enfrentamento ao \#CoronavírusNoBrasil.” (https://www.Facebook.com/watch/live/?v=211619416572835\&ref=watch_permalink), de 31/03/2020, que teve 31.500 curtidas, 32.700 comentários e mais de 12.000 compartilhamentos, 
anunciando logo no início da Pandemia as medidas de combate ao Covid-19 aprovadas pelo órgão.

No tocante às Assembleias Legislativas, a postagem de maior impacto foi o post da Assembleia Legislativa da Paraíba intitulado: "Mais um Projeto de Lei apresentado pela Assembleia no combate aos efeitos da pandemia foi sancionado pelo governador João Azevêdo. Para assegurar a saúde e o sustento alimentar de famílias carentes durante esse período atípico, a distribuição de cestas básicas para 260 mil alunos da rede estadual de ensino está aprovada. Quem tem fome tem pressa e a ALPB está trabalhando remotamente, todos os dias, para continuar beneficiando os paraibanos agora e sempre. \#ALPBumnovotempo". (https://www.Facebook.com/165715306870834/posts/2717514811690858/), de 06/05/2020, que obteve 4553 reações, 492 comentários e 513 compartilhamentos, indicando mais uma vez a relevância dos órgãos parlamentares para a aprovação de medidas de impacto social, especialmente junto à população mais carente. Por fim, em relação às Câmaras Municipais, a postagem com maior impacto foi uma divulgada em 24/03/2020 pela Câmara Municipal de Fortaleza, também lançando uma campanha para arrecadar cestas básicas para população carente atingida pela Pandemia (https://www.Facebook.com/160008874053393/posts /2728209670566621/), que obteve 5300 reações, 733 comentários e 1688 compartilhamentos até o momento da redação deste texto.

Em suma: as redes sociais serviram para divulgar um amplo repertório de ação, especialmente no campo social, muitas vezes flexibilizando políticas de ajuste fiscal dos executivos estaduais tendo em vista o contexto de Pandemia.

\section{Conclusão}

Podemos concluir o artigo inicialmente reiterando aquilo que já foi observado por outros autores, ou seja, a Pandemia marcou um salto qualitativo no processo de digitalização das atividades parlamentares, com o desenvolvimento de um amplo repertório de ações visando o combate à Pandemia, do qual a realização de sessões e votações remotas é apenas a dimensão mais visível. Verificamos também que tal processo se difundiu de maneira desigual em diversos parlamentos, com algumas casas legislativas apresentando baixo grau de uso das tecnologias digitais para a divulgação de suas atividades. Observamos ainda que os portais dos parlamentos federais, das assembleias legislativas e das câmaras municipais utilizaram amplamente das redes sociais, especialmente do Facebook, para divulgarem ações de enfretamento ao Covid-19 com um número elevado de postagens sobre o tema divulgando suas atividades.

Todos esses fatores colocam inúmeros desafios aos parlamentos digitais num contexto do pós-Covid 19. Se, por um lado, o enfrentamento da Pandemia mostrou a importância da 
digitalização das atividades parlamentares e da logística digital anteriormente desenvolvida pelos parlamentos (sessões remotas, votação digital, informatização dos processos operacionais do parlamento), por outro lado, revelou também a debilidade de alguns parlamentos, ainda sem condições de enfrentar os desafios colocados aos órgãos parlamentares na nova era digital. Não obstante, a ampla atividade exercida pelos parlamentos digitais durante o período da Pandemia mostra que estes podem servir com um contrapeso às medidas do Executivo, de certa forma "atenuando" as tendências ao populismo autoritário observadas em algumas democracias modernas (PEIXOTO, 2020). No entanto, observamos também que muitos parlamentos digitais em escala subnacional ainda são pouco atuantes. Ainda segundo o texto de Tiago Peixoto, três fatores podem explicar a resposta desigual dos parlamentos: a) responsividade política; b) capacidade administrativa; c) capacidade digital. No âmbito do presente estudo, procuramos apenas constatar esta desigualdade a partir de algumas evidências. Verificar a incidência destes três fatores em cada casa legislativa, é o programa de toda uma agenda de pesquisa a ser realizada em outros estudos posteriores.

Todos os fatores elencados e sobre os quais os dados deste artigo desenvolveram reflexão mostram que há diversas maneiras para os parlamentos inovarem se apropriando do digital para, ao contrário do que julga a percepção corrente em amplos setores da opinião pública e mesmo da literatura especializada, para os quais há uma tendência inexorável ao declínio dos parlamentos, reforçar valores democráticos, aumentando sua eficiência e credibilidade junto aos cidadãos a partir de uma aproximação entre a esfera de representação e a esfera civil. Nesse sentido, os parlamentos modernos estão colocados perante o dilema de ampliarem a digitalização de suas atividades, acompanhando o desenvolvimento da sociedade, ou se verem ultrapassados pelos acontecimentos, tornando-se menos relevantes por serem pouco permeáveis às mudanças e aos reclamos da sociedade e da esfera civil.

\section{Referências}

ALCÁNTARA SÁEZ, Manuel; GARCÍA MONTERO, Mercedes. ¿Parlamentos abiertos? Análisis comparado de la probidad y transparencia parlamentaria en América Latina. InterAmerican Development Bank, 2013.

BRAGA, Sérgio S.; MITOZO, Isabele B.; TADRA, Júlia. As funções desempenhadas pelos websites parlamentares brasileiros e o papel dos programas educativos. Educação \& Sociedade, v. 37, n. 136, p. 793-819, 2016.

BRAGA, Sérgio S.; MITOZO, Isabele B.; TADRA, Júlia. As funções educativas dos eparlamentos: uma análise longitudinal do caso brasileiro. Cadernos de Pesquisa, v. 46, n. 162, p. 1192-1215, 2016. 
BRASIL. Senado Federal. Coronavirus: Senado aprova auxílio emergencial de R\$600. Agência Senado, 30 mar. 2020. Disponível em: https://www12.senado.leg.br/noticias/materias/2020/03 /30/coronavirus-senado-aprova-auxilio-emergencial-de-r-600. Acesso em: 10 ago.2020

CHADWICK, Andrew. The hybrid media system: Politics and Power. 2. ed. Oxford: Oxford University Press, 2017.

COLEMAN, Stephen. Can the internet strengthen democracy? London: John Wiley \& Sons, 2017.

DALTON, Russell. Democratic Challenges, Democratic Choices: the erosion of Political Support in Advanced Industrial Democracies. Oxford: Oxford University Press, 2004.

FARIA, Cristiano F. O Parlamento aberto na era da internet: Pode o povo colaborar com o Legislativo na elaboração das leis? Brasília: Câmara dos Deputados, Edições Câmara, 2012.

GERBAUDO, Paolo. The digital party: Political organisation and online democracy. Pluto Press, 2019.

KEANE, John; ALONSO, Sonia; MERKEL, Wolfgang (org.). The future of representative democracy. Cambridge University Press, 2011.

LESTON-BANDEIRA, Cristina. The Impact of the Internet on Parliaments: a Legislative Studies Framework. Parliamentary Affairs, London, v. 60, n. 4, p. 655-674, 2007.

LESTON-BANDEIRA, Cristina; BENDER, David. How deeply are parliaments engaging on social media? Information Polity, v.18, p. 281-297, 2013.

LESTON-BANDEIRA, Cristina; THOMPSON, Louise. Exploring Parliament. Oxford University Press, 2018.

LEVITSKY, Steven; ZIBLATT, Daniel. How democracies die. New York: Broadway Books, 2018.

MEDEIROS, B. P., GOLDONI, L. R. F., BATISTA JUNIOR, E., \& ROCHA, H. R. D. O uso do ciberespaço pela administração pública na pandemia da COVID-19: diagnósticos e vulnerabilidades. Revista de Administração Pública, v. 54, n. 4, p. 650-662, 2020.

MENDONÇA, Ricardo Fabrino; FREITAS, Viviane Gonçalves. Fake News e o Repertório Contemporâneo de Ação Política. In: CONGRESSO DA ASSOCIAÇÃO BRASILEIRA DE PESQUISADORES EM COMUNICAÇÃO E POLÍTICA, 8, 2019. Anais [...]. Disponível em: http://compolitica.org/novo/wp-content/uploads/2019/05/gt1_mendonca_

freitas.pdf. Acesso em: 10 ago. 2020.

MEYER, Brett. Pandemic Populism: an analysis of Populist Leaders' Responses to Covid-19. London: Tony Blair Institute for Global Change. 2020. Disponível em: https://institute.global/policy/pandemic-populism-analysis-populist-leaders-responses-covid-19. Acesso em: 10 ago. 2020.

MITOZO, Isabele B. A utilização de sistemas deliberativos remotos pelas Assembleias Legislativas brasileiras durante a pandemia de Covid-19: características e prospectos. Revista do Legislativo Paranaense, Curitiba, n. 4, p.9-24, 2020.

NORTON, Philip. Parliaments: A framework for analysis. West European Politics, v. 13, n. 3 , p. 1-9, 1990. 
PEIXOTO, Tiago. Virtual parliaments in Times of Coronavirus: Flattening the Authoritarian Curve? 2020. Disponível em: https://democracyspot.net/2020/04/21/virtualparliaments-in-times-of-coronavirus-flattening-the-authoritarian-curve/. Acesso em: 10 maio 2020.

PEREIRA, A. K., OLIVEIRA, M. S., \& SAMPAIO, T. D. S. Heterogeneidades das políticas estaduais de distanciamento social diante da COVID-19: aspectos políticos e técnicoadministrativos. Revista de Administração Pública, v. 54, n. 4, p. 678-696, 2020.

PERSILY, Nathaniel. The 2016 US Election: Can democracy survive the internet? Journal of democracy, v. 28, n. 2, p. 63-76, 2017.

RECUERO, Raquel. Introdução à análise de redes sociais online. Salvador: UFBA, 2017

SANTOS, Fabiano. O processo legislativo na deliberação remota. Congresso Remoto Boletim, n. 1, 2020. Disponível em: https://olb.org.br/wp-content/uploads/2020/06/Boletim-OLBRegimento-Remoto_versaofinal.pdf. Acesso em: 15. ago. 2020.

WILLIAMSON, Andy. How are parliaments responding to the coronavirus pandemic? Hansard Society Blog, 2020. Disponível em: https://www.hansardsociety.org.uk/blog/how-areparliaments-responding-to-the-coronavirus-pandemic?. Acesso em: 15 abr. 2020. 
Anexo 1: Mídias Digitais utilizadas pelas casas legislativas brasileiras durante o período da Covid-19.

\begin{tabular}{|c|c|c|c|c|c|}
\hline $\mathbf{N}$ & Casa Legislativa & Facebook & Twitter & Youtube & Instagram \\
\hline 1 & Senado Federal & 1 & 1 & 1 & 1 \\
\hline 2 & Camara dos Deputados. & 1 & 1 & 1 & 1 \\
\hline 3 & Assembleia Legislativa do Paraná & 1 & 1 & 1 & 1 \\
\hline 4 & Assembleia Legislativa do Rio Grande do Sul & 1 & 1 & 1 & 1 \\
\hline 5 & Assembleia Legislativa de Santa Catarina & 1 & 1 & 1 & 1 \\
\hline 6 & Assembleia Legislativa de Espírito Santo & 1 & 1 & 1 & 1 \\
\hline 7 & Assembleia Legislativa de Minas Gerais & 1 & 1 & 1 & 1 \\
\hline 8 & Assembleia Legislativa do Rio de Janeiro & 1 & 1 & 1 & 1 \\
\hline 9 & Assembleia Legislativa de São Paulo & 1 & 1 & 1 & 1 \\
\hline 10 & Assembleia Legislativa do Acre & 1 & 0 & 0 & 0 \\
\hline 11 & Assembleia Legislativa do Amazonas & 1 & 1 & 1 & 1 \\
\hline 12 & Assembleia Legislativa do Amapá & 1 & 0 & 1 & 1 \\
\hline 13 & Assembleia Legislativa do Pará & 1 & 1 & 1 & 1 \\
\hline 14 & Assembleia Legislativa de Rondônia & 1 & 1 & 1 & 1 \\
\hline 15 & Assembleia Legislativa de Roraima & 1 & 1 & 1 & 1 \\
\hline 16 & Assembleia Legislativa de Alagoas & 1 & 1 & 1 & 1 \\
\hline 17 & Assembleia Legislativa da Bahia & 1 & 1 & 1 & 1 \\
\hline 18 & Assembleia Legislativa do Ceará & 1 & 1 & 1 & 1 \\
\hline 19 & Assembleia Legislativa do Maranhão & 1 & 1 & 1 & 1 \\
\hline 20 & Assembleia Legislativa da Paraíba & 1 & 1 & 1 & 0 \\
\hline 21 & Assembleia Legislativa de Pernambuco & 1 & 1 & 1 & 1 \\
\hline 22 & Assembleia Legislativa do Piauí & 1 & 0 & 1 & 0 \\
\hline 23 & Assembleia Legislativa do Rio Grande do Norte & 1 & 1 & 1 & 1 \\
\hline 24 & Assembleia Legislativa de Sergipe & 1 & 1 & 1 & 1 \\
\hline 25 & Assembleia Legislativa do Distrito Federal & 1 & 1 & 1 & 1 \\
\hline 26 & Assembleia Legislativa de Goiás & 1 & 1 & 1 & 1 \\
\hline 27 & Assembleia Legislativa do Mato Grosso do Sul & 1 & 1 & 1 & 1 \\
\hline 28 & Assembleia Legislativa do Mato Grosso & 1 & 1 & 1 & 1 \\
\hline 29 & Assembleia Legislativa do Tocantins & 1 & 1 & 1 & 1 \\
\hline 30 & Câmara Municipal de Rio Branco & 1 & 0 & 1 & 1 \\
\hline 31 & Câmara Municipal de Maceió & 1 & 1 & 1 & 1 \\
\hline 32 & Câmara Municipal de Manaus & 1 & 1 & 1 & 0 \\
\hline 33 & Câmara Municipal de Macapá & 1 & 1 & 1 & 1 \\
\hline 34 & Câmara Municipal de Salvador & 1 & 1 & 1 & 1 \\
\hline 35 & Câmara Municipal de Fortaleza & 1 & 1 & 1 & 1 \\
\hline 36 & Câmara Municipal de Vitória & 1 & 1 & 1 & 1 \\
\hline 37 & Câmara Municipal de Goiânia & 1 & 1 & 1 & 0 \\
\hline 38 & Câmara Municipal de São Luis & 1 & 1 & 1 & 1 \\
\hline 39 & Câmara Municipal de Belo Horizonte & 1 & $\mathrm{n}$ & 0 & 0 \\
\hline 40 & Camara Municipal de Campo Grande & 1 & 1 & 1 & 1 \\
\hline 41 & Câmara Municipal de Cuiabá & 1 & 1 & 1 & 1 \\
\hline 42 & Câmara Municipal de Belém & 1 & 1 & 1 & 1 \\
\hline 43 & Câmara Municipal de João Pessoa & 1 & 1 & 1 & 1 \\
\hline 44 & Câmara Municipal de Recife & 1 & 1 & 1 & 1 \\
\hline 45 & Câmara Municipal de Teresina & 1 & 0 & 1 & 1 \\
\hline 46 & Câmara Municipal de Curitiba & 1 & 1 & 1 & 1 \\
\hline 47 & Câmara Municipal de Rio de Janeiro & 1 & 1 & 1 & 1 \\
\hline 48 & Câmara Municipal de Natal & 1 & 1 & 1 & 1 \\
\hline
\end{tabular}




\begin{tabular}{|c|c|c|c|c|c|}
\hline 49 & Camara Municipal de Porto Velho & 0 & 0 & 1 & 0 \\
\hline 50 & Câmara Municipal de Boa Vista & 1 & 0 & 1 & 0 \\
\hline 51 & Câmara Municipal de Porto Alegre & 1 & 1 & 1 & 0 \\
\hline 52 & Câmara Municipal de Florianópolis & 1 & 1 & 1 & 1 \\
\hline 53 & Câmara Municipal de Aracaju & 1 & 1 & 1 & 1 \\
\hline 54 & Câmara Municipal de São Paulo & 1 & 1 & 1 & 1 \\
\hline 55 & Câmara Municipal de Palmas & 1 & 1 & 1 & 1 \\
\hline
\end{tabular}

